\title{
A escrita performática de João Gilberto Noll
}

\section{Paloma Vidal}

Resumo: $\mathrm{O}$ artigo aborda dois romances recentes de Joâo Gilberto Noll, Berkeley em Bellagio (2002) e Lorde (2004), relacionando sua escrita com a arte da performance, $\mathrm{A}$ correspondència é ùtil na medida em que se trata de uma escrita que aspira a abolir as fronteiras entre literatura $e$ vida para se tornar um experimento com o corpo do próprio escritor. O protagonista desses romances é o escritor brasileiro, sem meios, que vè no convite de instituiçỏes estrangeiras a possibilidade de garantir temporariamente șa sobrevivència, Viajar deflagra o experimento que levará o eu ao limite de sua dissoluçào. Palavras-chave: Joâo Gilberto Noll, performance, corpo, viagem.

Abstract: The article approaches two novels by João Gilberto Noll, Berkeley em Bellagio (2002) and Lorde (2004), relating their writing to performance art. The correspondence is useful in so far as it is a writing that aspires to abolish the boundaries between literature and life to become an experiment with the body of the own writer. The main character of these novels is the Brazilian writer, without means, that sees in the invitation of foreign institutions the possibility of temporarily warranting his survival. Travelling deflagrates the experiment that will take the $I$ to the limit of its dissolution. Keywords; loào Gilberto Noll, performance, body, truvel. 
João Gilberto Noll começou a publicar no início dos anos 1980 e desde então vem reconfigurando os cenários desolados da pós-modernidade com uma escrita modelada pela errância. Desde seu primeiro livro, $O$ cego e a dançarina, vemos surgir uma pergunta acerca do destino de uma geração órfã, suspensa na incerteza do futuro, como o protagonista do conto de abertura, que se depara com a necessidade de fazer "alguma coisa urgentemente" diante do pai moribundo. Sem pai, os personagens de Noll sairão em busca de algo indefinido, dando testemunho da insistência de um desejo que os mantém vivos. O desejo os move, os faz abandonar o lar e ganhar as ruas. A cada novo livro, a errância recomeça: o personagem, que é sempre um homem despojado de tudo, anda pela cidade, deixando-se afetar pelo mundo à sua volta, embora não espere dele mais do que a simples possibilidade de continuar vagando, abandonado a uma contingência que aparentemente não tem muito a lhe oferecer, mas acabará proporcionando-lhe alguns encontros intensos. Em dois de seus romances mais recentes, Berkeley em Bellagio e Lorde, o personagem errante é o próprio escritor, brasileiro e sem meios, que vê no convite de instituições estrangeiras a possibilidade de garantir temporariamente sua sobrevivência e não "ter de mendigar de novo em seu país de origem". 'Uma vez mais nesses textos, o personagem se abandona a um roteiro urbano incerto, só que neles é afirmada uma identificação com o escritor: "Deste lado eu, que tinha vivido aqueles anos, vamos dizer, nu no Brasil, sem amigos, vivendo aqui e ali dos meus livros, no menor intervalo a escrever mais, passando maus pedaços e todo cheio de piruetas para disfarçar minha precariedade material" 2 Para além do que os dados biográficos confirmam de maneira mais evidente que em livros anteriores, já que Noll efetivamente passou temporadas nos lugares onde transcorrem os romances, o instigante nesses textos é

\footnotetext{
* Algumas das ideias apresentadas aqui foram desenvolvidas anteriormente em dois artigos: "Performance e homoafetividade em dois romances de João Gilberto Noll" (e-misférica: performance y politica en las América, www.hemisphericinstitute.com, volume 4.1), sobre a aproximaçāo entre escrita e performance como modo de fazer surgir um encontro com o outro definido a partir da noção de homoafetividade; e "Comunidades inadecuadas: la narrativa reciente de J. G. Noll" (Revista Grumo, n. 5, 2007), sobre as formas de comunidade propostas por Berkelley em Bellagio e Lorde como resistência à indiferença pós-moderna. Esta nova elaboração me permitiu aprofundar a noção de "escrita performática" em sua rel ação com a errância própria desses dois romances.

1 NOLL, João Gilberto. Berkeley em Bellagio. São Paulo: W11, 2004, P. 9.

2 Idem, Lorde. São Paulo: W11, 2004, p. 11.
}

Teresa revista de Literatura Brasileira [10|11]; São Paulo, p. 298-309, 2010. - 301 
como a aproximação entre escritor e personagem permite retrabalhar a experiência da errância, numa escrita que chamarei de "performática".

Como veremos, o termo performance se mostra útil para abordar uma escrita que aspira a abolir as fronteiras entre literatura e vida, tornando-se um experimento com o corpo do próprio escritor. Herdeira das vanguardas, uma das características fundamentais da performance é questionar os limites da arte, aproximando-a da vida. Quando o performer faz do seu corpo material de trabalho, está deliberadamente questionando o distanciamento que funda a ideia de obra e apostando na possibilidade de que ela seja uma experimentação subjetiva mais do que uma representação da realidade. Não se trata necessariamente de uma inflação narcísica, embora esse seja um risco a ser calculado; em todo caso, o que se destaca em relação aos textos de Noll é, inversamente, a performance como exposição de um eu precário, que constantemente se coloca em questão, indagando sobre sua identidade, como neste trecho de Berkeley em Bellagio: "quem sou?, por que provoco tamanha curiosidade alheia?, o que que faço?, se é isso que todos querem ver, enfim, eu sou alguém que nada faz, que nada tem, nem ao menos o seu próprio corpo."

Jorge Glusberg, em $A$ arte da performance, estabelece uma genealogia da performance a partir dos movimentos vanguardistas do início do século $\mathrm{xx}$, referindo-se à "longa batalha para liberar as artes do ilusionismo e do artificialismo". ${ }^{4}$ Ele faz referência às "Noites futuristas" italianas, que incluíam recitais poéticos, apresentações de música e dança, leituras de manifestos e representações teatrais; aos futuristas russos, que levaram as apresentações às ruas, realizando uma turnê por várias cidades do país; ao cabaré Voltaire, em Zurique, onde começaram a se reunir os fundadores do movimento Dadá e se faziam também leituras de poemas, apresentações musicais e exposições de pinturas; à Paris dos anos 1920, onde os mesmos dadaístas realizaram soirées e também excursões pela cidade. Delas participaram os futuros surrealistas, cuja reivindicação de uma arte que trabalhasse com o inconsciente, rompendo com o pensamento lógico, foi também fundamental para o desenvolvimento da performance como forma artística. Na mesma direção, Glusberg menciona a liberação proposta por Artaud, em seu manifesto de 1932, para que o "homem possa assumir sua posição entre o sonho e a realidade", que tirou o teatro do campo do realismo, permitindo que o corpo entrasse em cena como tal para eliminar a distância entre ator e espectador.

3 NOLL, João Gilberto. Berkeley em Bellagio, op. cit., p. 53.

4 GLUSBERG, Jorge. A arte da performance. São Paulo: Perspectiva, 2005, p. 46. 
Como parte da história da performance, Glusberg inclui também o happening e a body art. Batizado por Allan Kaprow quando apresentou 18 Happenings em 6 partes, em 1959, numa galeria de Nova Iorque, o happening surgiu como um evento coletivo, que convocava a participação do público. Seguindo um rigoroso roteiro, os performers de 18 Happenings executavam ações cotidianas, leituras de textos, proferiam monólogos, mostravam filmes e slides, tocavam instrumentos de brinquedo etc. Glusberg vê em John Cage e Jackson Pollock os antecedentes desse tipo de manifestação, que considera uma nova forma de collage, como o foi o Untitled event, um espetáculo apresentado por Cage em 1952, que buscava a fusão de cinco artes - teatro, poesia, pintura, dança, música - para formar uma sexta linguagem que experimentasse com o acaso e a indeterminação; e também o action painting, uma colagem de imagens que transformava o ato de pintar em tema e o pintor em ator, praticada por Pollock durante os dez últimos anos de sua vida. Se no action painting, o corpo entra no espaço artístico, um pouco mais tarde, no final dos anos 1960, ele se tornará a própria obra na body art, que agrupa diversas tendências da dança, do teatro e do happening. Glusberg situa sua estreia pública no final dos anos 1970, em três ações: a de Vito Acconci, que realiza Following Piece, seguindo várias pessoas na rua; a de Michel Journiac, que apresenta Messe pour um corps, em que o público é convidado a comungar do seu próprio sangue; e a de Daniel Buren, que faz suas andanças Dans les rues de Paris. Trata-se de desfetichizar o corpo, que não é mais um objeto da arte, visto de fora, exaltado através da representação, mas sujeito de uma ação em que a arte e a vida se indistinguem.

Seguindo o percurso de Glusberg, fica a pergunta sobre como distinguir a performance de manifestações tão próximas como o happening ou a body art. Uma observação do próprio autor é esclarecedora nesse sentido: a performance seria "um gênero mais amplo", com duas marcas fundamentais particularmente pertinentes na aproximação com a escrita de Noll - a presença física do artista e seu caráter antirrepresentacional. Renato Cohen, em seu livro Performance como linguagem, busca examinar esses dois aspectos de maneira mais sistemática. No capítulo " $\mathrm{Da}$ linguagem", Cohen assinala que antes de mais nada a performance é uma pesquisa da linguagem, produzida através de um trabalho interdisciplinar, buscando integrar as artes, mas não como um Gesamtkunstwerk, no sentido wagneriano de integração harmoniosa; pelo contrário, a fusão de linguagens se dá através da collage. Cohen analisa então essa técnica, definindo-a, a partir de Max Ernst, como "justaposição e colagem de imagens não

5 Idem, ibidem, p. 43.

Teresa revista de Literatura Brasileira [10|11]; São Paulo, p. 298-309, 2010. - 303 
originalmente próximas, obtidas através da seleção e picagem de imagens encontradas, ao acaso, em diversas fontes". ${ }^{6}$ Central nas vanguardas, a collage será reapropriada de diferentes maneiras a partir de então. No caso da performance, ela favorece a utilização do que Cohen denomina uma "linguagem gerativa", que rompe com a gramática discursiva para trabalhar com o fragmento a partir da livre associação, gerando sentidos e imagens inesperados. Favorece também a preponderância do colador, cujo inconsciente será explorado na ação.

No capítulo "Da atuação". a performance é compreendida como um evento, que acontece aqui e agora, como o teatro. Só que, enquanto o teatro tendeu a acentuar a representação, a performance enfatiza a atuação, quebrando com a ilusão cênica ao problematizar as fronteiras entre o tempo "ficcional" e o tempo "real". A performance se apresenta como um work in progress, aberta para o improviso e para o imprevisível. "Isso cria", afirma Cohen, "a característica do rito, com o público não sendo mais só espectador, e sim, estando numa espécie de comunhão"? Há uma cumplicidade maior entre o performer e o público, e também uma confrontação maior, na medida em que o performer muitas vezes o interpela e se deixa interpelar por ele. A performance busca uma transformação dos participantes no presente da atuação. Em especial, o corpo do performer será um espaço de experimentação, o espaço do encontro com o outro, capaz de gerar várias possibilidades imprevistas. É esse espaço de experimentação que Noll busca transpor para o texto, com uma escrita que força seu próprio limite para expor o corpo em ação. Já em $A$ fúria do corpo, seu primeiro romance, encontramos uma exposição do eu através de uma linguagem excessiva que elude a representação. Assim começa o romance:

O meu nome não. Vivo nas ruas de um tempo onde dar o nome é fornecer suspeita. A quem? Não me queira ingênuo: nome de ninguém não. Me chame como quiser, fui consagrado a João Evangelista, não que o meu nome seja Joāo, absolutamente, não sei quando nasci, nada, mas se quiser o meu nome busque na lembrança o que de mais instável lhe ocorrer. ${ }^{8}$

Noll insiste em suas entrevistas que não lhe interessa contar uma história; o que está em jogo é a produção de uma experiência de linguagem em que a escrita se

\footnotetext{
6 COHEN, Renato. Performance comolinguagem. São Paulo: Perspectiva, 2004, p. 60.

7 Idem, ibidem, p. 97.

8 NOLL, João Gilberto. A fúria do corpo. Rio de Janeiro: Record, 1981, p. 25.
} 
abra para o que possa surgir de inesperado, daí que se trate de uma linguagem ligada ao inconsciente, uma "linguagem gerativa", nos termos de Cohen, antirrepresentativa, que procura reduzir a distância entre quem escreve e quem lê. Nesse sentido, vale destacar dois aspectos do trecho citado acima: a narração no presente, que é uma forma de criar um efeito de simultaneidade, como se o que estamos lendo estivesse sendo produzido naquele momento mesmo, ao invés de reproduzir algo previamente dado; e, estreitamente ligado ao primeiro aspecto, o apelo ao outro por meio da segunda pessoa. Está começando aí uma travessia por "inéditas rotas" cujo "roteiro é o corpo", como diz o narrador em dado momento, e da qual o leitor é solicitado a participar.

Se desde seus primeiros textos Noll faz da escrita um experimento com o corpo em ação, em Berkeley em Bellagio e Lorde a indefinição entre personagem e escritor intensificará seu efeito performático, na medida em que o corpo que se expõe agora é o do próprio escritor, gastado pela precariedade, que "já não conseguia obter o entusiasmo necessário por povoar enfim esse mundo congelado do Norte". 9 Esse homem que se sente velho ainda assim empreende novas travessias: em Berkeley em Bellagio, passa uma temporada na Universidade de Berkeley, Califórnia, como professor visitante, e depois é convidado por uma fundação americana para se dedicar à elaboração de seu novo romance, em Bellagio, Itália; em Lorde, abandona o pouco que tem em Porto Alegre por "uma graninha extra" em Londres, onde vai cumprir uma missão profissional a convite de um inglês que mal conhece. Nos dois casos, trata-se de um homem maduro, que não parece ter nada a aprender, mas que também não parece poder oferecer a "decantada sabedoria do idoso". ${ }^{10}$ Para que viaja esse homem? No ensaio, "A viagem e uma viagem", Denílson Lopes analisa o retorno da imagem da viagem na literatura contemporânea como uma atualização da discussão em torno da Bildung. "Por que e para que aprender? É possível uma vida como aprendizado?"," pergunta o crítico, com o objetivo de problematizar o paradigma iluminista "que implicava a socialização do indivíduo, na passagem da infância para

9 Idem. Lorde, op. cit., p. 21.

10 Idem, ibidem, p. 25.

11 LOPES, Denílson. O homem que amava rapazes e outros ensaios. Rio de Janeiro: Aeroplano, 2003, p. 166. 
a vida adulta, e, ao mesmo tempo, a constituição de um sujeito singular e autônomo, a partir de um aprendizado interior, progressivo e por etapas". ${ }^{12}$ A narrativa de Noll dialoga com essa problemática, constituída desde o início, como vimos, em torno da errância, que, embora impossibilite uma aprendizagem nos moldes iluministas, talvez possa ser o ponto de partida para uma versão contemporânea do Bildungsroman. Nessa versão, a viagem, ao invés de facilitar o encontro do eu consigo próprio, leva ao estranhamento e à deformação.

Em Berkeley em Bellagio, a viagem se inicia no campus da universidade americana. Passeando pelos bosques de Berkeley, "descia-lhe a ilusão de uma orgia intimista e conclusiva que o brindaria transportando-o para fora daquele campus, daquele país, do mundo até quem sabe" ${ }^{13}$ A inadequação do escritor o faz ver com desconfiança o impulso humanitário da aluna americana, que "queria ajudar na erradicação daquela pobreza em natureza abastada que nem conseguia imaginar direito"; 14 desconfia dessa crença na filantropia, como se "o desenvolvimento dos países pobres dependesse de mutirões de dedicados voluntários desta nação aqui com dois oceanos". ${ }^{15}$ Desconfia também da onipotência de uma nação que acredita poder inclusive salvar o mundo com sua boa vontade, como se se tratasse de um único e indiferenciado território indigente à espera apenas de sua caridade.

A inadequação se acentua em Bellagio, diante do descompasso entre o que o escritor esperava encontrar num vilarejo do interior da Itália, cuja imagem herdou do cinema italiano clássico, e os turistas e caminhões de obra que atravancam as ruas da cidade. Também não consegue encaixar-se entre os scholars patrocinados pela fundação Rockefeller. Um deles, um equatoriano que trabalha numa gigantesca fundação filantrópica, expõe-lhe o plano para a salvação da América Latina. "A realidade é um jogo", sustenta. "Todos devem jogar seu jogo até o fim, [...] essa a razão de estarmos aqui. $O$ aperfeiçoamento das regras do jogo? - ah, a única promessa"; ; um outro, professor de sociologia em Minneapolis, pretende escrever uma obra chamada Toward a more equitable world e tem também a salvação do mundo na ponta da língua:

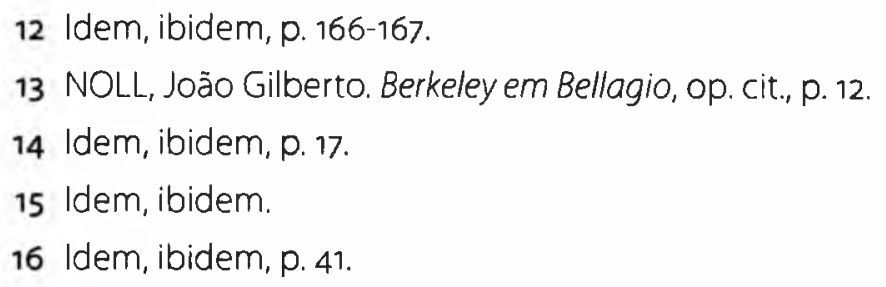


acabar com os governos corruptos, desentravar o processo democrático em cada região, pegando a tal, a mitológica oportunidade a todo cidadão, um cidadão que poderia com orgulho se espelhar, ou melhor, se inspirar, perdão, a cada manhã na Democracia Americana. ${ }^{17}$

Na língua é onde essa inadequação se manifesta mais certeiramente. "Ele não falava inglês" é a frase que abre o romance. "Ele caminhava entre esquilos pelo campus de Berkeley e pensou que não adiantava se lembrar de quase nada; precisava mesmo era ir à ação, falar inglês, testemunhar nessa língua a todos que pudessem se interessar por sua vida". ${ }^{18}$ A língua é o que faz a mediação entre o escritor e o país estrangeiro. Num primeiro momento, ele se sente isolado, alienado até, por essa língua que ele não domina. Quer aprender a nova língua para poder mergulhar no novo universo. Aos poucos, no entanto, é invadido pelo temor de ser abandonado por sua própria língua e, desse modo, também por sua escrita: "todos pareciam querer sair do abrigo da língua portuguesa, menos ele, escritor, que temia se extraviar de sua própria língua sem ter por consequência o que contar" 19

Na passagem de Berkeley a Bellagio, o inglês passa a acossá-lo: "já não conseguia processar um pensamento que não fosse em inglês", ${ }^{20}$ percebe alarmado. A partir de então, o português terá que competir com o "súbito inglês dentro de mim". "O fluente e repentino inglês do personagem se, por um lado, retira-o da condição de pária na catedral de scholars, por outro, extravia-o de casa", afirma Analice Martins. ${ }^{22}$ Se ele agora resolvesse voltar para Porto Alegre, teria que enfrentar sua nova condição:

como um gringo desvalido, sem saber o que fazer de mim numa cidade que eu já não reconheço, não sei meu endereço, não lembro de parente, se perguntam onde fica essa tal rua eu nada entendo, se sou eu a perguntar alguma coisa é a outra pessoa a me olhar sem dar rumo ao pensamento, o inglês é minha língua de repente..$^{23}$

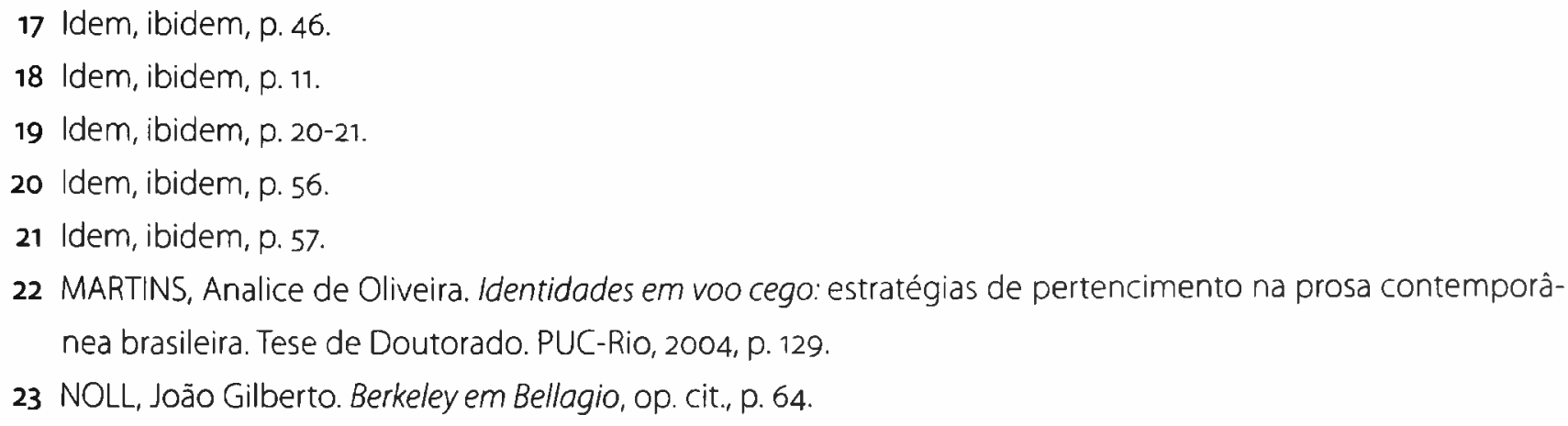


Assim, da condição de estrangeiro que não fala a língua do lugar, passa a estrangeiro em sua própria língua, numa viagem que parece não ter volta: "se o português ao menos retornasse, se eu pudesse me virar novamente em Porto Alegre". ${ }^{24}$ Esse processo de estranhamento linguístico progressivo está ligado a uma condição que o escritor enunciara anteriormente:

disse-lhe em meu inglês esfarrapado que eu era o caçula de uma família de nove irmãs, e que me sentia um sobrevivente de mares femininos, que me perdoasse então pelo fato de ser assim aéreo, como se nunca tivesse conseguido o fio pedestre de nenhuma fala, em qualquer língua. ${ }^{25}$

No choque com a língua estrangeira, fica em evidência uma indisposição consigo mesmo, o vestígio de sua condição de estrangeiro no universo feminino. "Quem me responde, e já, se o fato de eu estar aqui andando pelo bosque em plena madrugada me confere alguma garantia de que eu não seja um outro que de fato sou, um estrangeiro de mim mesmo". ${ }^{26}$ A viagem descortina, assim, uma condição subjetiva frágil, instável, e também permeável ao que a errância possa trazer de novo. "No trajeto da escrita", afirma Ítalo Moriconi na orelha da edição de 2003, "o eu oscila entre celebrar e sustar sua autodissolução. O eu se constrói e se dissolve, ao mesmo tempo".

É essa oscilação do eu que acompanhamos ao longo do livro, como uma performance em que o escritor se transforma diante de nós. A escrita é um trajeto que percorremos com ele, vertiginosamente, num longo parágrafo que vai do começo ao fim do livro. Como sugere Moriconi, acompanhamos seu impulso de autodissolução, que se expressa exemplarmente no deslizamento da primeira para a terceira pessoa e vice-versa; e também o movimento correspondente de construção, ou reconstrução, uma tentativa de "começar tudo de novo, voltar a ser aquele que eu era antes de me meter em Berkeley e Bellagio". ${ }^{27}$ Essa labiríntica trajetória se resolve no final com um reencontro com a língua, a cidade e o amante. "Começo a compreender na alma onde estou, com quem estou, há quanto tempo, não faz muito eu sei, alguns minutos, devagarinho vou ganhando a lembrança do meu português, a

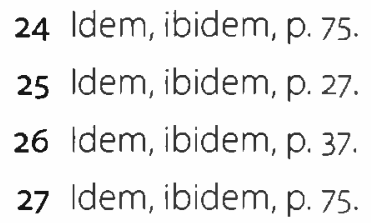


língua sai de mim em pedacinhos" ${ }^{28}$ A errância, pela primeira vez nas narrativas de Noll, abre a possibilidade de uma aprendizagem, embora provisória, que consiste em estar com o outro mesmo sem compreendê-lo.

Em Lorde, o escritor desembarca em Londres atrás de um desejo que se acredita perdido, atrás talvez da morte, encarando a cada esquina sua própria decadência. A viagem serve para testar os limites do eu, que se aventura a sair de si para quem sabe "alcançar aquele ponto onde tudo vaza para o infinito" 29 Desde o momento em que pisa no aeroporto, ele se sente lançado na incerteza. Mal conhece o homem que o contratou, a cidade lhe é estranha, não sabe que missão deve cumprir. Mesmo depois do encontro com o scholar inglês, ele não consegue achar-se; não consegue definir o que está fazendo ali, por que foi chamado, como deve agir. "Talvez caísse como uma luva para o seu projeto se eu morresse sem saber o nome, a direção, um simples fio que eu pudesse seguir até chegar a alguma coisa que parecesse com sentido", ele pensa. Essa inquietação o fará sair pela cidade, onde viverá uma experiência de dissolução do eu mais extrema ainda do que em Berkelley em Bellagio. "Tinha vindo para Londres para ser vários", ${ }^{30}$ anuncia.

Depois de deixar suas malas na casa que o inglês alugara para ele em Hackney, pega um ônibus que o leva até Oxford Street. Dali atravessa o Soho até chegar a Piccadilly Circus, onde entra numa loja de cosméticos e compra um pó de arroz. Diante do espelho do banheiro da National Gallery, ele se maquia para iniciar sua travessia: "Tirei a caixinha do bolso, retirei o estojo, abri-o e passei a esponja lentamente pelas faces, testa. Se alguém me visse pensaria logo na performance de algum artista". ${ }^{31}$ No dia seguinte, num cabeleireiro unissex, põe em prática a segunda etapa de seu travestismo, pintando seus escassos cabelos de castanho-claro. A partir de então, nada de espelhos. "Eu não teria mais face, evitaria qualquer reflexo dos meus traços" ${ }^{32} \mathrm{Seu}$ rosto será agora o de um outro, quem sabe um lorde, decadente como deve ser um

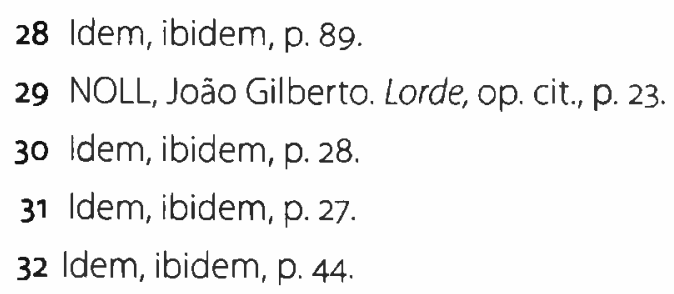


lorde no início do século xxI, perdido num subúrbio da capital inglesa, "um bairro que eu sabia longínquo, ao norte de Londres, de imigrantes vietnamitas, turcos, já fora das margens dos mapas da cidade que costumam propagar em folders turísticos ${ }^{33}$ Se em Berkeley em Bellagio o escritor não poupa de sua ironia os intelectuais bem-intencionados que fazem alarde de seus planos de salvação do mundo, espelhados no governo americano e financiados por ele, Lorde mostra o outro lado dessa Pax Americana.

Lá dentro falavam português, iraniano, chinês, vietnamita, inglês, espanhol, italiano, turco. O que vinham empreender naquelas ruas que, à medida que Hackney se aproximava, iam ficando cada vez mais feias, sujas, atribuladas por obras intermináveis? Tinha sérias dúvidas de que vivessem melhor naqueles becos de Londres do que na sua escassez natal..$^{34}$

Enquanto o escritor se abandona à errância pelas ruas da cidade estrangeira, longe da proteção do inglês que supostamente deveria zelar por seu bem-estar, a narrativa vai sendo tomada por um tom paranoico. "Qual o interesse de um militar inglês em me ter na Inglaterra? Que serviço eu poderia prestar às armas ou às relações armadas entre os dois países?", ${ }^{35}$ o escritor se pergunta. De repente, de alguém contratado para uma missão mais ou menos indefinida, torna-se um prisioneiro, um "escravo de uma maquinação secreta", ${ }^{36}$ arrastado por alucinações alimentadas pela nova paranoia global.

Dali em diante, tudo se precipita, e o escritor decide fugir para o interior da Inglaterra. "O desafio desse sujeito é articular suas máscaras em constante troca, seu eu mutante sem se deixar dissolver no puro movimento, na velocidade, no mercado das imagens", ${ }^{37}$ assinala Denílson Lopes a respeito dos novos viajantes. Noll aposta nessa dissolução, talvez mais radicalmente do que nunca em Lorde: "eu desconfiava seriamente de que eu já não trazia o mesmo homem." ${ }^{38}$ Mas pode ser que essa dissolução se mostre como "outra fonte de formação": "essa fonte viria dali, daquele

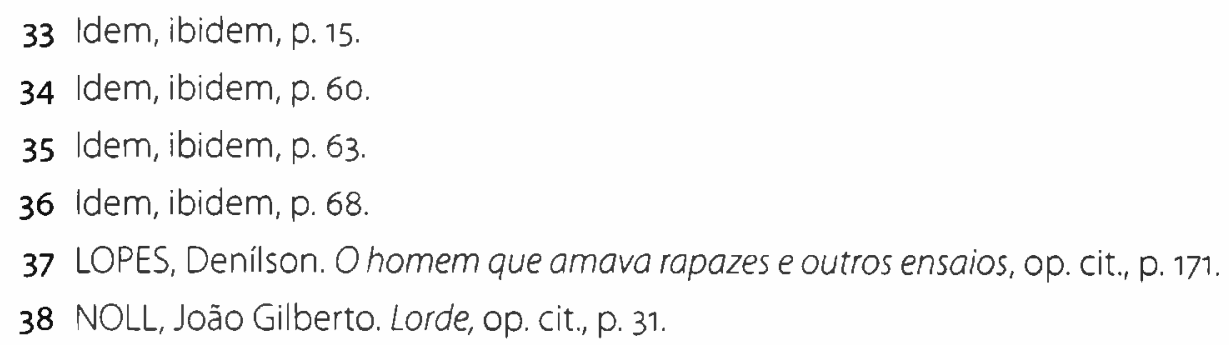


homem de cabelos castanho-claros, com a maquiagem recomposta, vivendo em Londres por enquanto sem lembrar com precisão por quê" ${ }^{39}$ Pode ser que "desse material difuso" seja possível extrair um "novo rosto", uma "nova memória".40 A possibilidade de ser outro é bem-vinda pelo escritor, como se lhe fosse dada a oportunidade de nascer de novo, de deixar para trás o velho eu, esse que escreveu sete livros e que já não consegue encontrar-se nem neles nem no seu corpo. Lorde é uma travessia sem destino certo, uma aposta no desconhecido, cujos efeitos não se podem medir de antemão; uma viagem de aniquilação do eu que termina com uma estranha fusão com o outro, em que o eu desaparece para dar lugar a um novo ser, que o contém, mas não é ele. "Eu sou o professor de português, repeti o leve acento gaúcho, com a mesma disposição, a minha, só que em outra superfície, mais incisiva, oleosa, a melena espessa de bárbaro, a dele", ${ }^{41}$ lemos ao chegar ao fim da narrativa, quando numa última viagem, de Londres a Liverpool, o narrador se funde a um inglês, dono de uma loja de ferragens, que conhece num bar. A escrita se aproxima da performance na travessia de um eu que afirma uma identidade entre personagem e escritor para melhor expor sua desagregação, experimentando com os limites do seu corpo a ponto de transformá-lo em outro. Para o leitor que acompanha esse experimento, os cenários mundializados por onde transita o escritor nunca mais serão os mesmos.

Paloma Vidal é professora de Teoria Literária da Universidade Federal de São Paulo e autora de Mais ao Sul (Língua Geral, 2008); A história em seus restos: literatura e exílio no Cone Sul (Annablume, 2004); A duas mãos (7 Letras, 2003).

39 Idem, ibidem, p. 32.

40 Idem, ibidem, p. 34.

41 Idem, ibidem, p. 109.

Teresa revista de Literatura Brasileira [10|11]; São Paulo, p. 298-309, 2010 - 311 